\title{
A Small Step towards Big Data: Trends and Preference Patterns in Ophthalmic Oncology
}

\author{
Arun D. Singh \\ Department of Ophthalmic Oncology, Cole Eye Institute, Cleveland Clinic Foundation, \\ Cleveland, Ohio, USA
}

\section{Key Words}

Trends $\cdot$ Preferences $\cdot$ Ocular tumors $\cdot$ Melanoma $\cdot$ Retinoblastoma

\begin{abstract}
Purpose: To record trend and preference patterns among ocular oncologists for commonly encountered clinical diagnoses or scenarios. Methods: Participants responded anonymously to a PowerPoint presentation of questions encompassing the spectrum of ophthalmic oncology (with illustrations) using an audience response system. Each question was displayed for about $1 \mathrm{~min}$ and results were immediately projected before presenting the next question. The wordings of the 33 questions that were directly related to patient care, case illustrations, and the graphic representation of the responses (in the sequence of presentation) are reproduced herein. Results: Responses were recorded for participant demographics, retinoblastoma, uveal melanoma, adult intraocular tumors, retinal tumors, and conjunctival, eyelid and orbital tumors. Conclusions: Such data collection efforts should be ongoing and comprehensive to collect information on trends, practice preferences, and guidelines in absence of hard evidence.
\end{abstract}

(C) 2014 S. Karger AG, Basel

\section{Introduction}

Managing patients with rare and exotic conditions can be exciting as well as challenging. Such 'orphan diseases' do not attract federal or private funds to conduct prospective studies that generate high-quality data. Moreover, with only a few cases of a given diagnosis managed even in specialized clinics, there are not enough numbers of patients to undertake any meaningful statistical analysis. Hence, management of many ophthalmic oncology patients is driven by an 'expert opinion' rather than statistical evidence. The situation may get even murkier if 
Fig. 1. Responses to the survey.

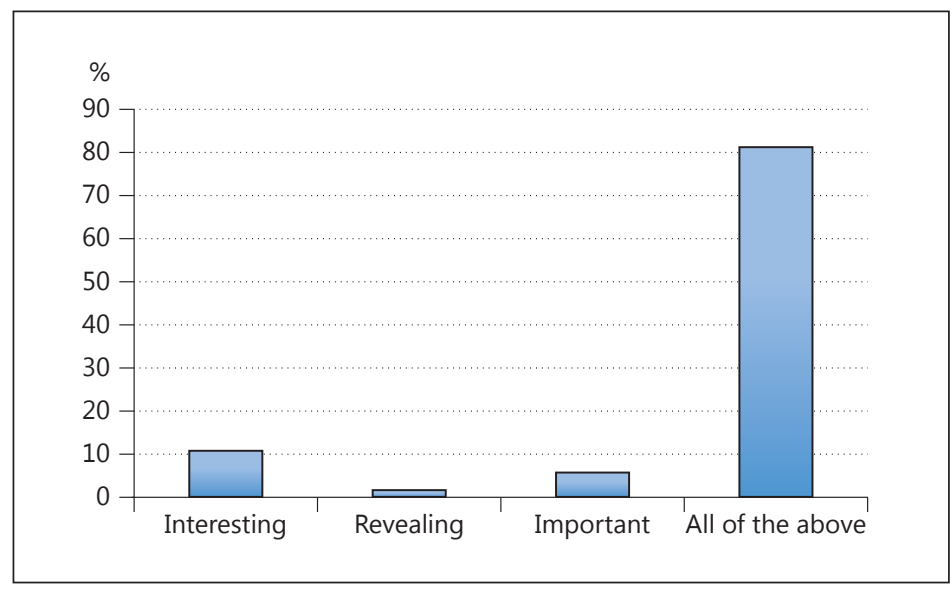

the experts were to offer differing opinions. The likelihood of such differing opinions is perhaps proportional to the rarity of the disease.

After realizing the limits of what is possible, one can either perpetuate the status quo or, alternatively, generate data on 'preference patterns'. Such data may serve as background reference to allow comparison with any rendered 'expert opinion'. Although far from being a perfect solution, such data would offer insight to an expert as to the extremeness of his opinion, provide alternatives to the rendered opinion, and also be reassuring to the patients (if supported by the majority).

To our knowledge, this paper records first attempts at generating trend and preference patterns among ocular oncologists for commonly encountered clinical diagnoses or scenarios.

\section{Methods}

At the 16th congress of the International Society of Ocular Oncology held in October 2013 (Cleveland, Ohio, USA), a special session was conducted wherein the participants responded anonymously to a PowerPoint presentation of questions encompassing the spectrum of ophthalmic oncology (with illustrations) using an audience response system. Each question was displayed for about 1 min and results were immediately projected before presenting the next question. The wordings of the 33 questions that were directly related to patient care, case illustrations, and the graphic representation of the responses (in the sequence of presentation) are reproduced herein.

\section{Results}

\section{Participant Demographics}

Although not all participants responded to every question, the predominant composition of the audience was of delegates from North/Central/South America and Europe who felt that the survey was interesting and revealing, and that it was important to gather such information ( $\mathrm{n}=119$ ) (fig. 1$)$. There was an equal distribution of those in practice for $<5,5-10$, $10-20$, and 20 years $(n=122)$ (fig. 2$)$ with the majority practicing full-time ophthalmic oncology ( $n=124)$ (fig. 3).

\section{Retinoblastoma}

First-line treatment for unilateral macular retinoblastoma in a 6-month-old infant (group C, International Classification) was intra-arterial chemotherapy by the majority (52\%) with 
Ocular Oncology

and Pathology

Fig. 2. Participant demographics (years in practice).

\begin{tabular}{l|l}
\hline Ocul Oncol Pathol 2015;1:39-53 \\
\hline DOI: 10.1159/000366561 & $\begin{array}{l}\text { ○ 2014 S. Karger AG, Basel } \\
\text { www.karger.com/oop }\end{array}$ \\
\hline
\end{tabular}

Singh et al.: A Small Step towards Big Data: Trends and Preference Patterns in Ophthalmic Oncology
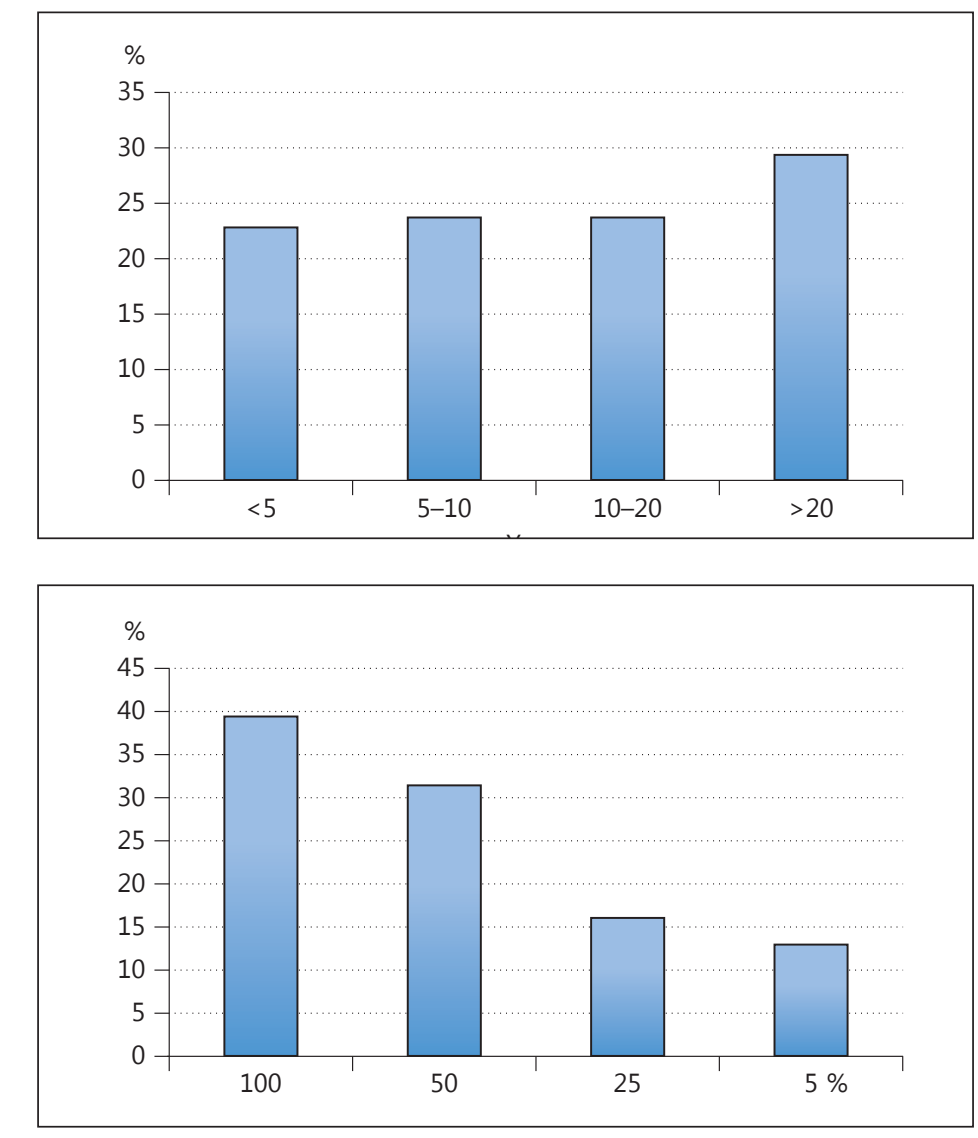

Fig. 3. Participant demographics (percent time oncology practice).

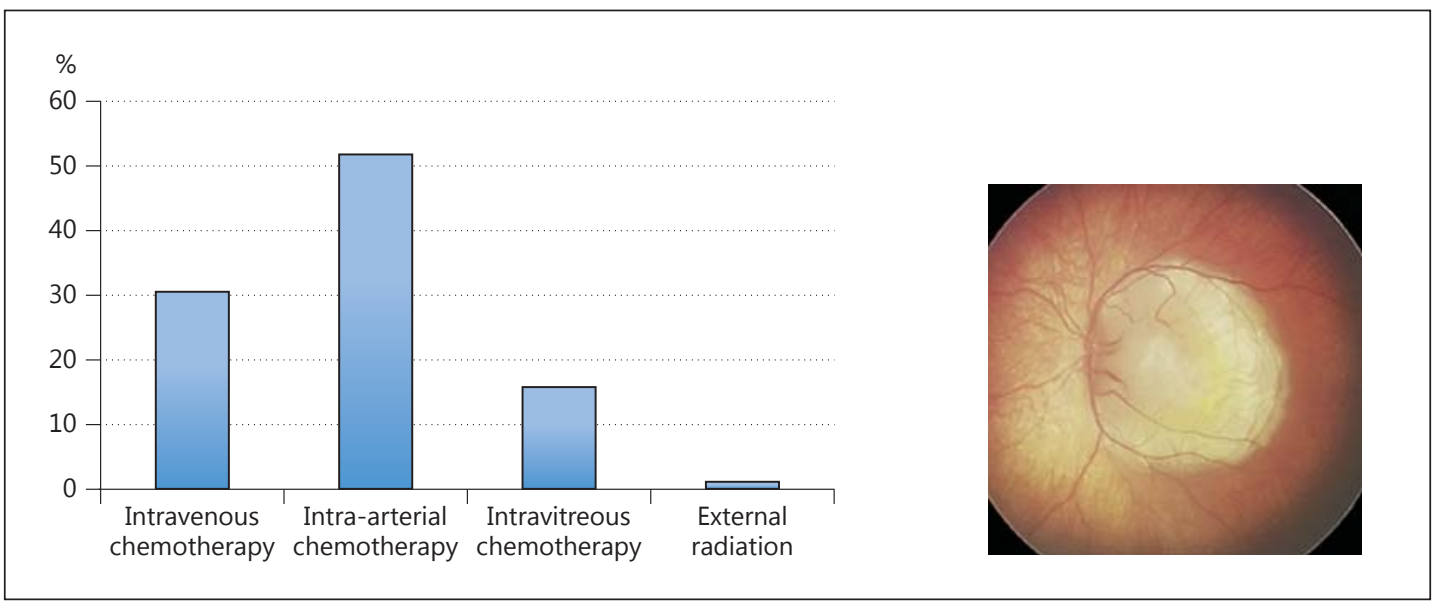

Fig. 4. First-line treatment of a unilateral macular retinoblastoma in a 6-month-old infant (group C, International Classification). Reproduced with permission from: Sethi RV, MacDonald SM, Kim DY, Mukai S: Radiation therapy: retinal tumors. Dev Ophthalmol 2013;52:58-74.

only $1 \%$ favoring external radiation therapy (fig. 4). However, first-line treatment for diffuse retinoblastoma (group E, International Classification) preferred by the large majority (71\%) was enucleation (fig. 5).

Postprimary enucleation adjuvant therapy was considered by the vast majority (91\%) if high risk factors were present on histopathology (fig. 6). There was no clear preference for 
Ocular Oncology

and Pathology

Fig. 5. First-line treatment for diffuse retinoblastoma (group E, International Classification).

Fig. 6. Adjuvant therapy: postprimary enucleation for retinoblastoma. (1) Consider adjuvant therapy if a high-risk pathology is present. (2) Do not discuss adjuvant therapy. (3) Do not assess high-risk pathology factor. (4) Every case receives adjuvant therapy after enucleation.

Fig. 7. Recommendations for imaging surveillance for trilateral retinoblastoma. (1) Only for germline cases. (2) Only for familial cases. (3) For all retinoblastoma cases. (4) I do not perform surveillance.

\begin{tabular}{l|l}
\hline Ocul Oncol Pathol 2015;1:39-53 \\
\hline DOI: 10.1159/000366561 & $\begin{array}{l}\text { @ 2014 S. Karger AG, Basel } \\
\text { www.karger.com/oop }\end{array}$ \\
\hline
\end{tabular}

Singh et al.: A Small Step towards Big Data: Trends and Preference Patterns in Ophthalmic Oncology
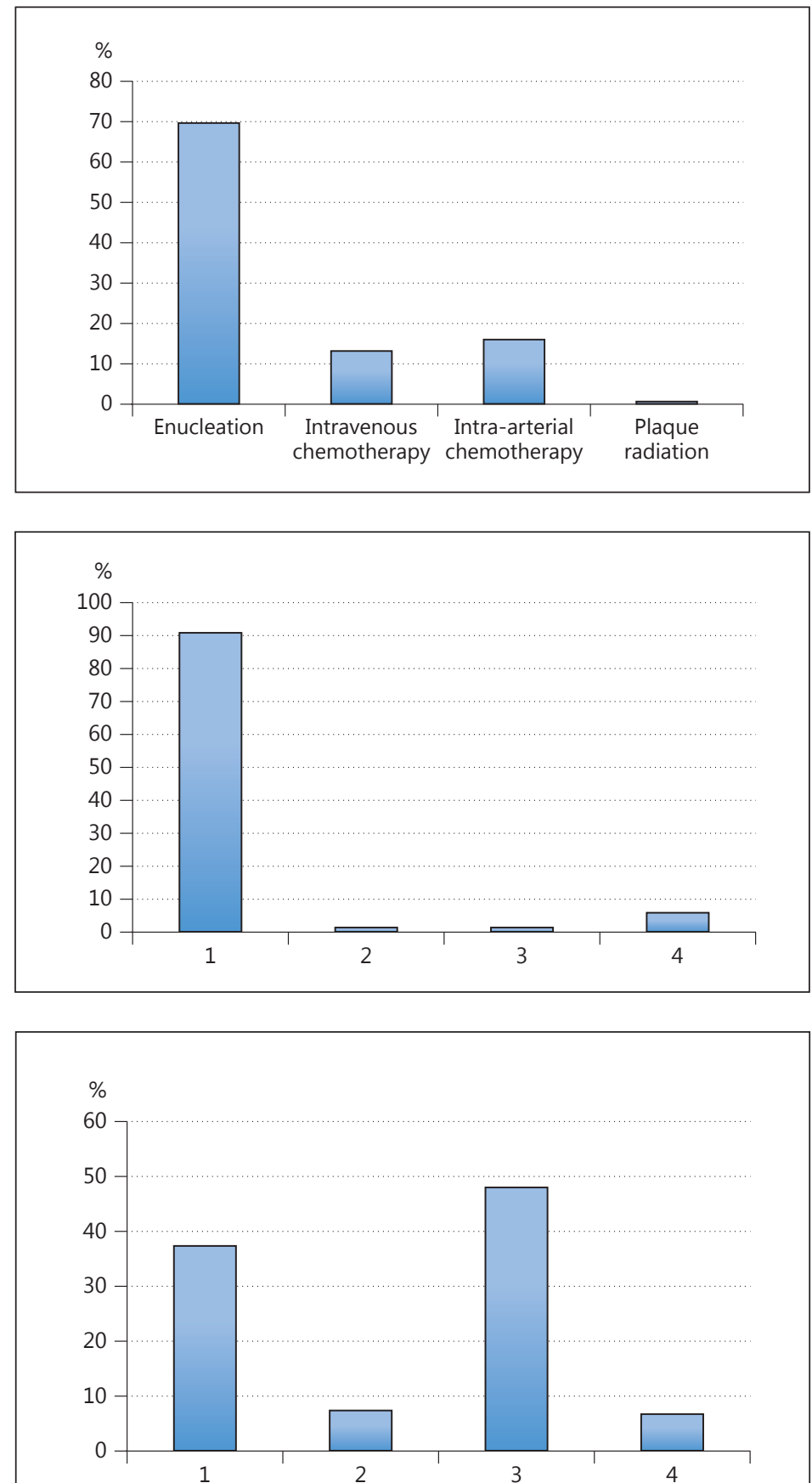

imaging surveillance for trilateral retinoblastoma, as 38\% performed it only for germline cases whereas almost half (48\%) would recommend it for all cases of retinoblastoma. Only a minority (8\%) did not perform surveillance (fig. 7). Several participants perceived barriers for widespread use of intra-arterial chemotherapy such as high cost (11\%), lack of ancillary expertise (19\%), availability of effective alternatives (17\%), and all of the above (54\%) (fig. 8). 
Fig. 8. Perceived barriers for widespread use of intra-arterial chemotherapy. (1) High cost. (2) Lack of ancillary expertise. (3) Availability of effective alternatives. (4) All of the above.

\section{DOI: 10.1159/000366561}

(c) 2014 S. Karger AG, Base www.karger.com/oop

Singh et al.: A Small Step towards Big Data: Trends and Preference Patterns in Ophthalmic Oncology

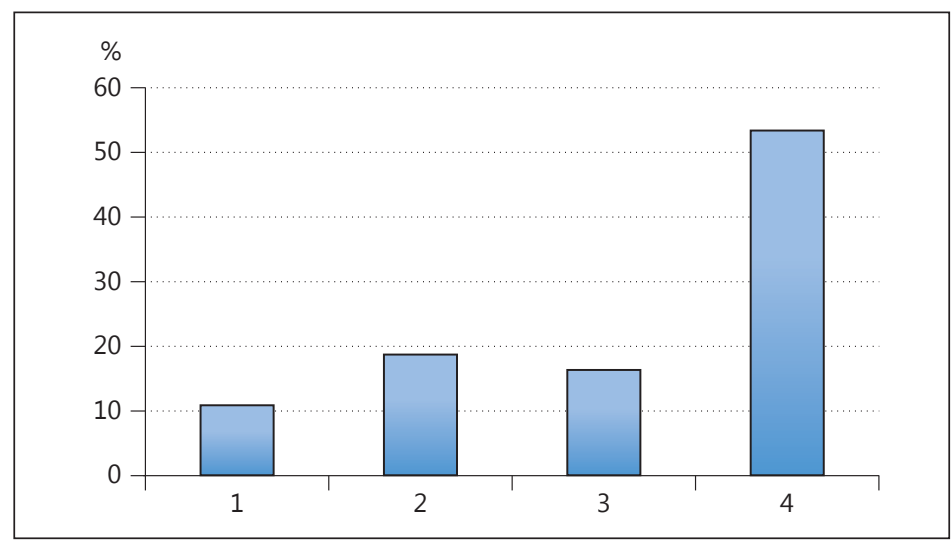

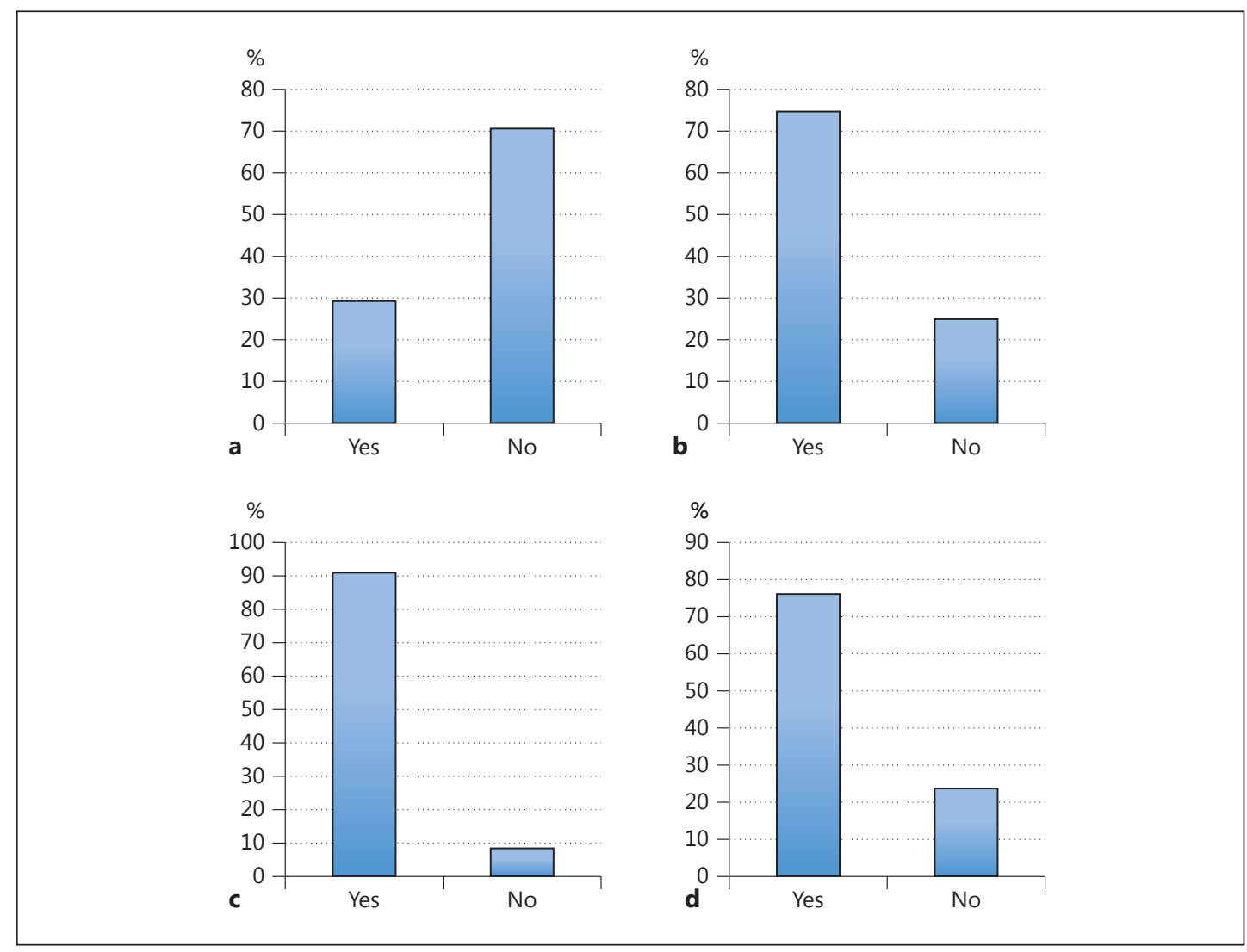

Fig. 9. Predicting the future of chemotherapy for retinoblastoma. a Increased role of intravenous chemotherapy. b Increased role of intra-arterial chemotherapy. c Increased role of intravitreal chemotherapy. d Increased role of targeted therapy.

Most respondents felt that there would be an increased role of intra-arterial chemotherapy (75\%), intravitreal chemotherapy (91\%), and targeted therapy (76\%), whereas there would be a decline in usage of intravenous chemotherapy (71\%) (fig. 9).

\section{Uveal Melanoma}

The majority (47\%) would recommend observation as the initial method of treatment for a pigmented iris lesion. Only one third (33\%) recommended sector iridectomy for this 


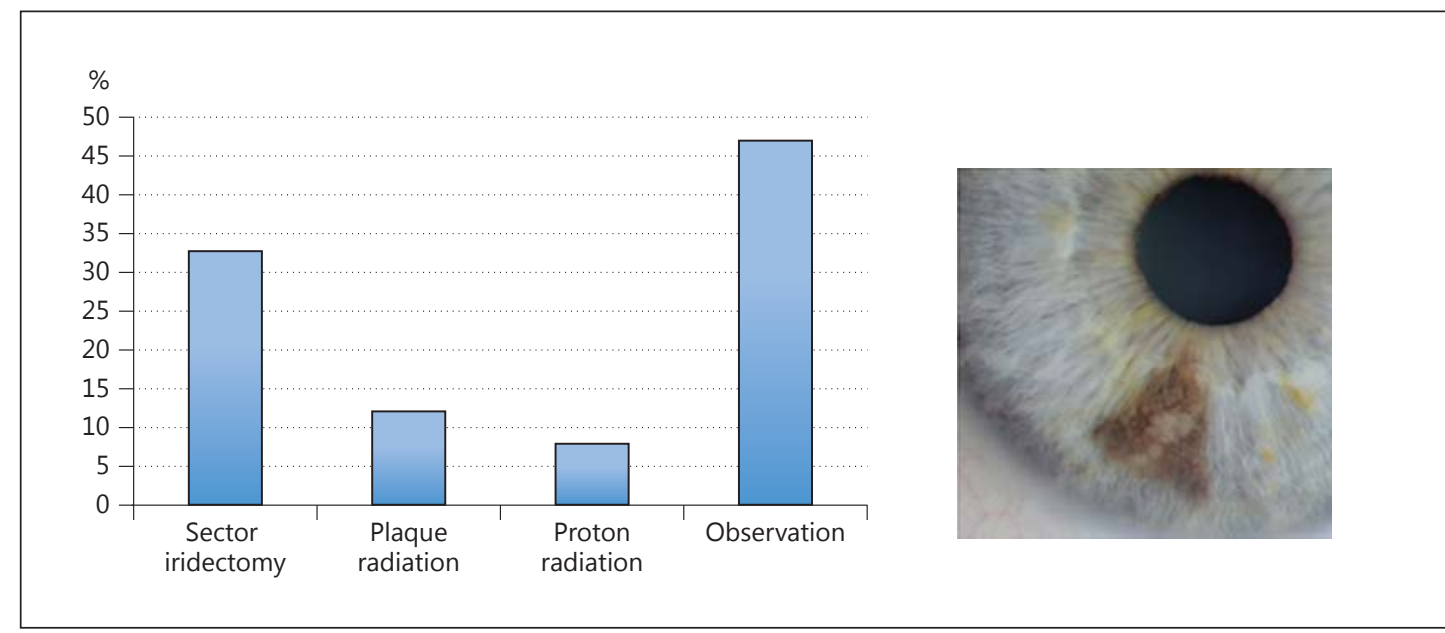

Fig. 10. Initial method of treatment for a localized pigmented iris lesion that did not extend up to the angle.

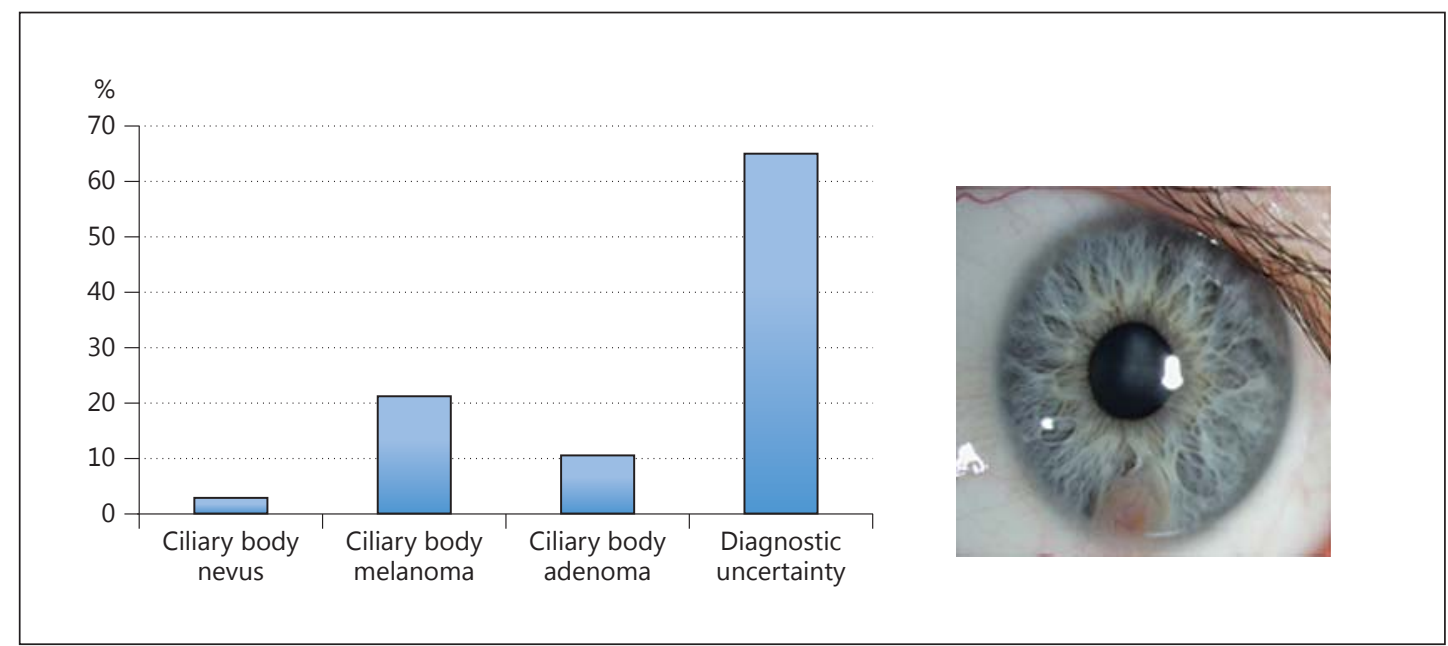

Fig. 11. Suspected clinical diagnosis. Amelanotic iris lesion that was incidentally observed on evaluation for contact lenses in a 20-year-old man. Visual acuity was 20/20 with normal IOP.

case that was eventually confirmed histopathologically as iris melanoma (fig. 10). In a case of an amelanotic iris lesion that was incidentally observed on evaluation for contact lenses in a 20-year-old man, the majority (65\%) expressed diagnostic uncertainty (fig. 11). A choroidal lesion that was incidentally observed in a 45-year-old woman with $20 / 20$ vision $(10 \times 10 \times$ $2.5 \mathrm{~mm}$ in size) was labeled as indeterminate melanocytic lesion by the majority (55\%). An alternative terminology of large (9\%) and suspicious nevus (21\%) was also used (fig. 12). A choroidal lesion in a 45-year-old man that was $7.0 \times 6.5 \times 1.9 \mathrm{~mm}$ in size, with visible orange pigmentation (lipofuscin) and drusen, was classified as melanoma by the majority (44\%). Only a minority labeled it as indeterminate melanocytic lesion (14\%) (fig. 13). The majority (61\%) would treat such a tumor by radiation therapy, whilst only an extreme minority (1\%) would perform enucleation (fig. 14). Overall, $25 \%$ of the respondents did not use transpupillary thermotherapy (TTT) and only $6 \%$ would use it as a sole treatment for a small choroidal melanoma. The majority used TTT in combination with radiation therapy (41\%) (fig. 15). 
Singh et al.: A Small Step towards Big Data: Trends and Preference Patterns in

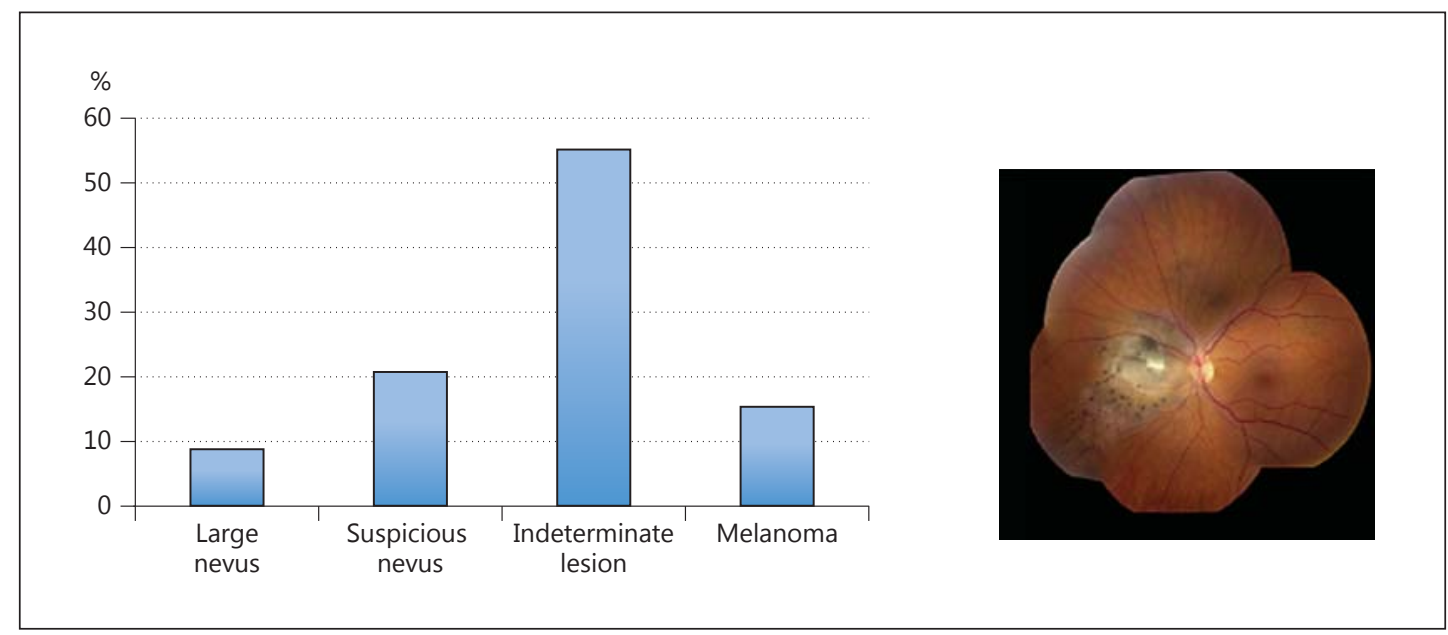

Fig. 12. Suspected clinical diagnosis. Choroidal lesion that was incidentally observed in a 45-year-old woman with $20 / 20$ vision $(10 \times 10 \times 2.5 \mathrm{~mm}$ in size $)$.

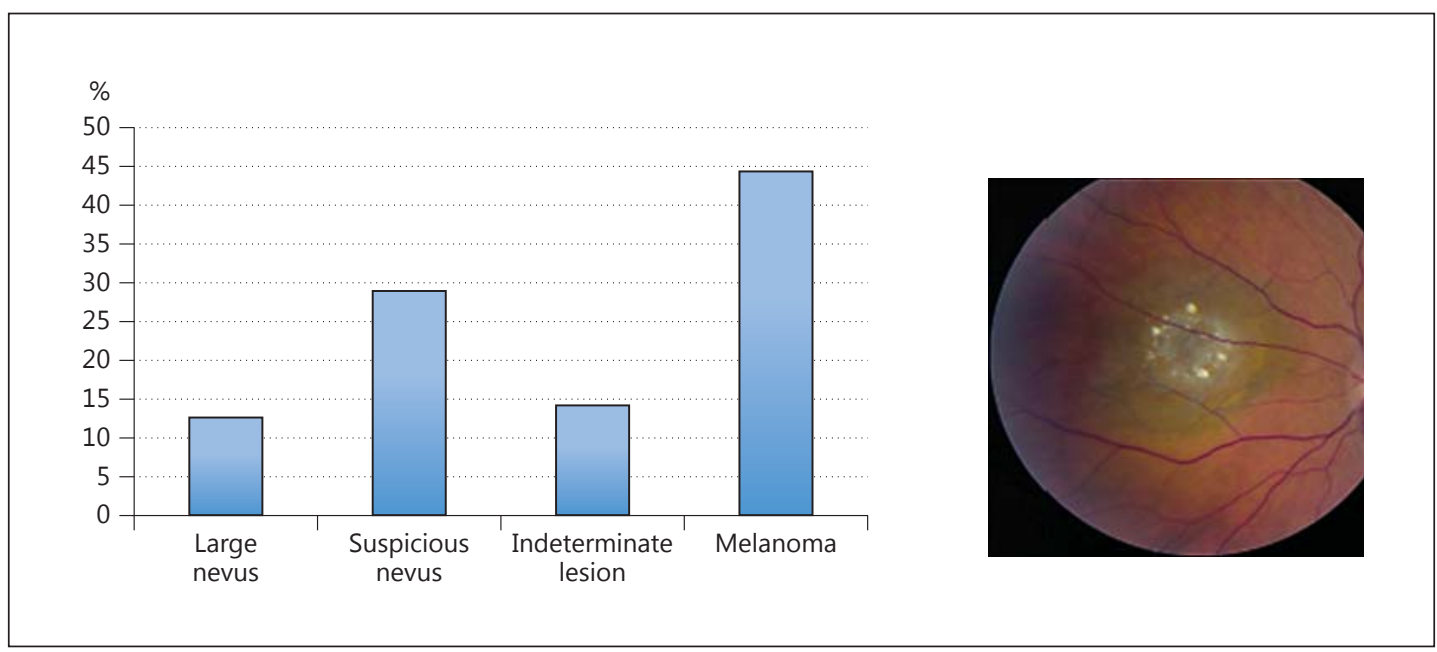

Fig. 13. Suspected clinical diagnosis. Choroidal lesion in a 45-year-old man that was $7.0 \times 6.5 \times 1.9 \mathrm{~mm}$ in size with visible orange pigmentation (lipofuscin) and drusen.

In a case of amelanotic choroidal tumor clinically suspected to be choroidal melanoma, about one third (34\%) would not perform diagnostic or prognostic biopsy, whereas $40 \%$ would do biopsy for both diagnostic and prognostic purposes (fig. 16). Regarding prognostication, the majority (40\%) did not offer it to their patients. The most commonly used prognostication method was gene expression profiling (30\%), whereas others used cytogenetic (15\%) or DNA-based methods (15\%) (fig. 17).

The majority offered surveillance for uveal melanoma metastases including some form of liver imaging (85\%). Only the minority of respondents did not perform surveillance (4\%) or did not include liver imaging in their surveillance protocol (4\%) (fig. 18). If the prognostication result was favorable (low risk of metastases), the majority of participants informed their patients of the test results but did not alter the surveillance protocol. However, if the prognostication result was unfavorable (high risk of metastases), the majority of participants 
and Pathology

Fig. 14. Preferred treatment for the case shown in figure 13.
Ocular Oncology

\begin{tabular}{l|l}
\hline Ocul Oncol Pathol 2015;1:39-53 \\
\hline DOI: 10.1159/000366561 & $\begin{array}{l}\text { @ 2014 S. Karger AG, Basel } \\
\text { www.karger.com/oop }\end{array}$ \\
\hline
\end{tabular}

Singh et al.: A Small Step towards Big Data: Trends and Preference Patterns in Ophthalmic Oncology

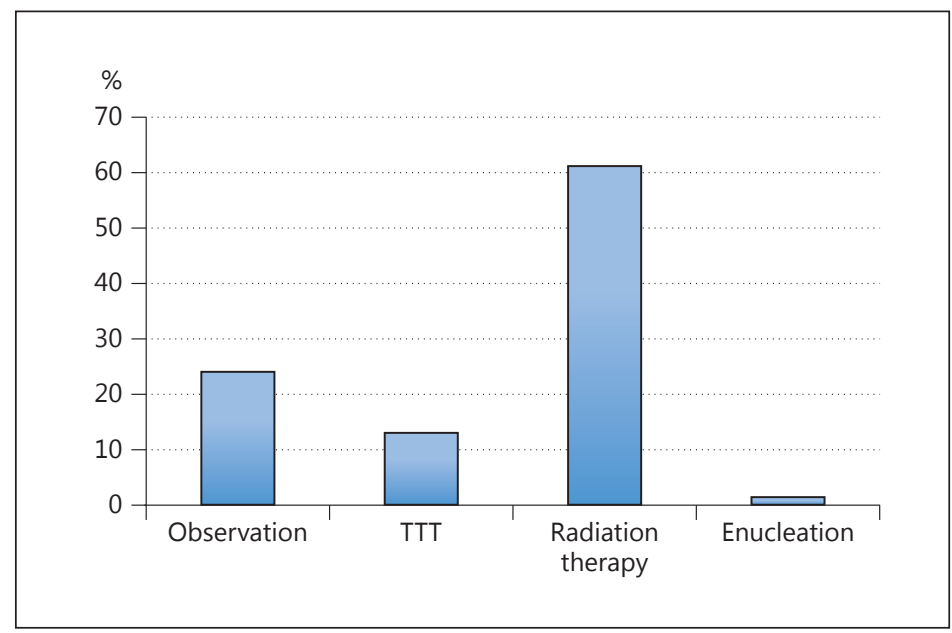

Fig. 15. Uveal melanoma: use of TTT. (1) As sole therapy for small choroidal melanoma. (2) In combination with radiation therapy. (3) Sole or in combination. (4) I do not use TTT.

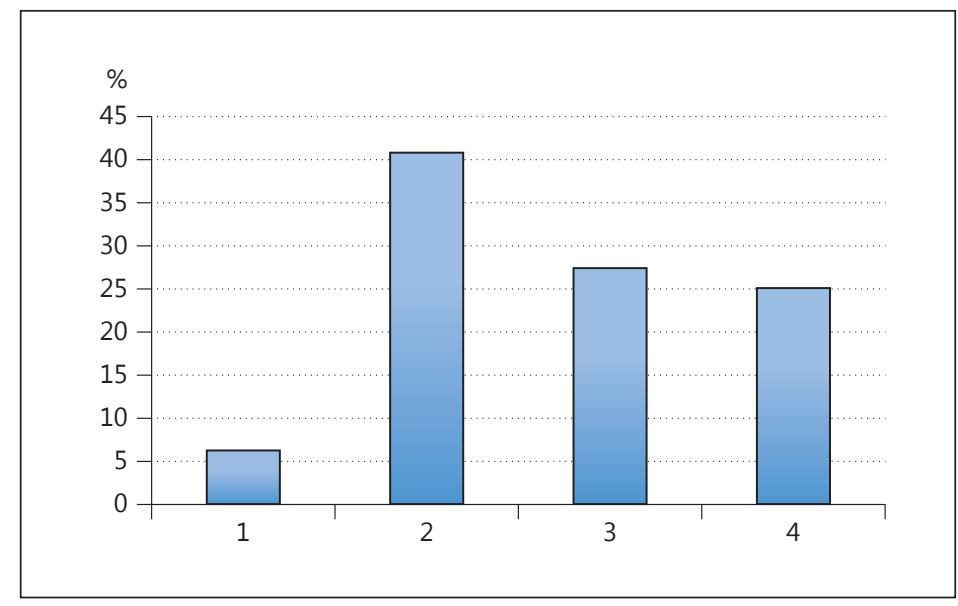

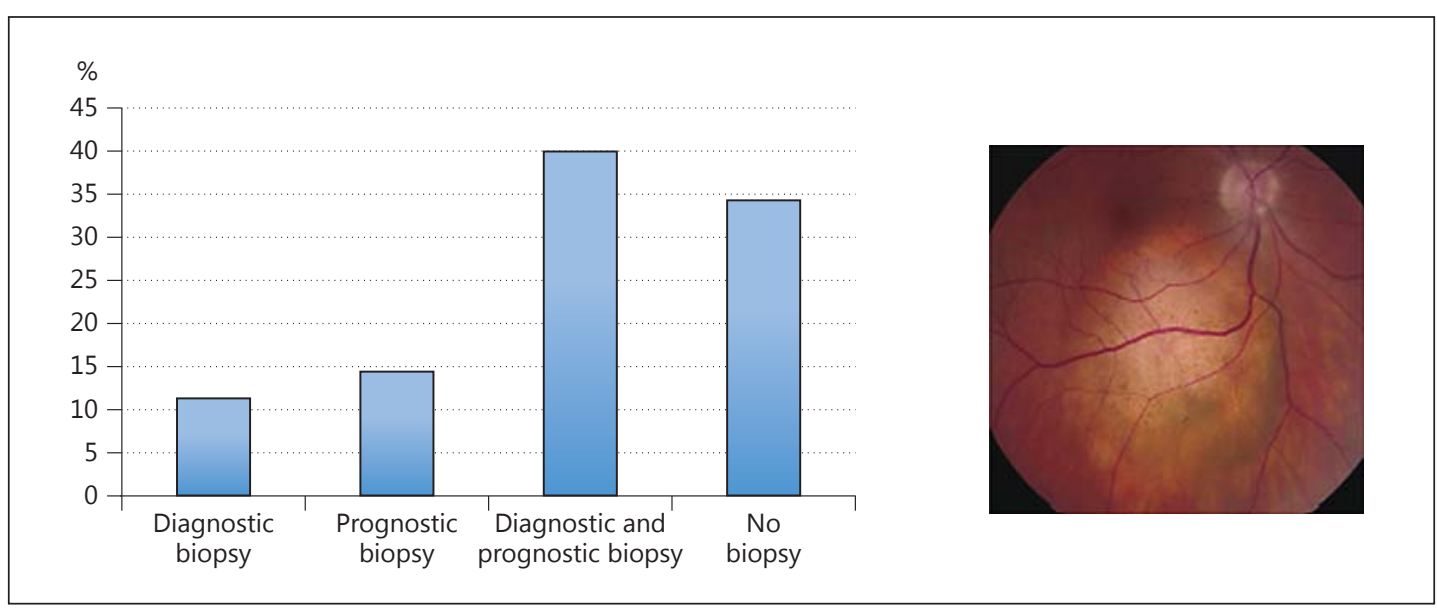

Fig. 16. Role of biopsy in a case of amelanotic choroidal tumor clinically suspected to be choroidal melanoma. Reproduced with permission from: Biscotti CV, Singh AD: Uveal metastases. Monogr Clin Cytol 2012;21: 17-30. 
Ocular Oncology

and Pathology

Fig. 17. Techniques used for prognostication in uveal melanoma. (1) FISH, cytogenetics, or related technique. (2) MLPA, MSA, SNP or related technique. (3) Gene expression profiling. (4) I do not offer prognostication.

Fig. 18. Surveillance for uveal melanoma metastases. (1) No periodic surveillance. (2) Surveillance without liver imaging. (3) Surveillance with liver imaging. (4) Surveillance with PET scan.

Fig. 19. Clinical implications of prognostication results. (1) I do not inform the patient of the result. (2) The patient is informed, but there is no difference in surveillance. (3) The patient is informed, and there is an increase/ decrease in surveillance. (4) The patient is informed and offered experimental adjuvant therapy.

\begin{tabular}{l|l}
\hline Ocul Oncol Pathol 2015;1:39-53 \\
\hline DOI: 10.1159/000366561 & $\begin{array}{l}\text { @ 2014 S. Karger AG, Basel } \\
\text { www.karger.com/oop }\end{array}$ \\
\hline
\end{tabular}

Singh et al.: A Small Step towards Big Data: Trends and Preference Patterns in Ophthalmic Oncology
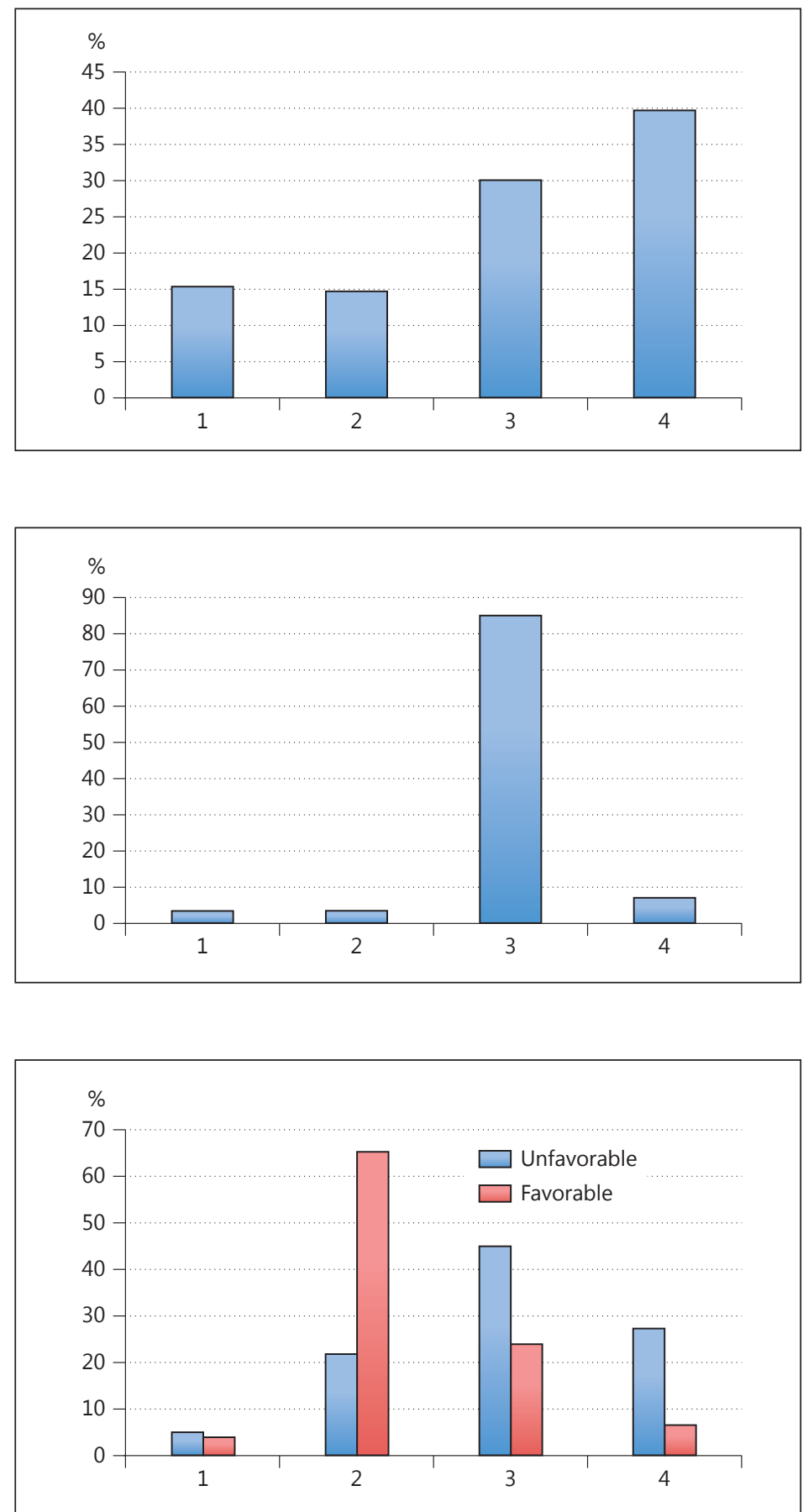

informed their patients of the test results and increased the frequency/intensity of the surveillance protocol. Patients with unfavorable prognosis were more likely to be considered for adjuvant therapy (27 vs. $7 \%$ ) (fig. 19).

\section{Other Intraocular Tumors}

Treatment of radiation retinopathy (maculopathy, visual acuity of 20/30) was recommended by the majority with the OCT-guided anti-VEGF therapy (44\%) (fig. 20). Acute radi- 
Ocular Oncology

and Pathology

Fig. 20. Treatment of radiation retinopathy following treatment of choroidal melanoma located in the nasal quadrant (CME with visual acuity of 20/30). (1) OCTguided anti-VEGF therapy. (2) Fluorescein angiogram-guided laser photocoagulation. (3) Photocoagulation and anti-VEGF therapy. (4) Observation.

\begin{tabular}{l|l}
\hline Ocul Oncol Pathol 2015;1:39-53 \\
\hline DOI: 10.1159/000366561 & $\begin{array}{l}\text { ( 2014 S. Karger AG, Basel } \\
\text { www.karger.com/oop }\end{array}$ \\
\hline
\end{tabular}

Singh et al.: A Small Step towards Big Data: Trends and Preference Patterns in Ophthalmic Oncology

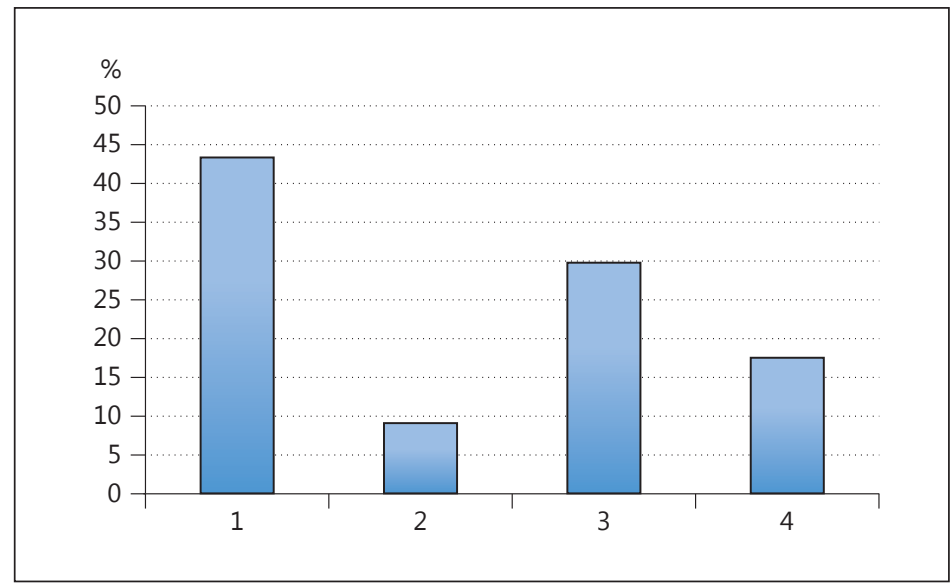

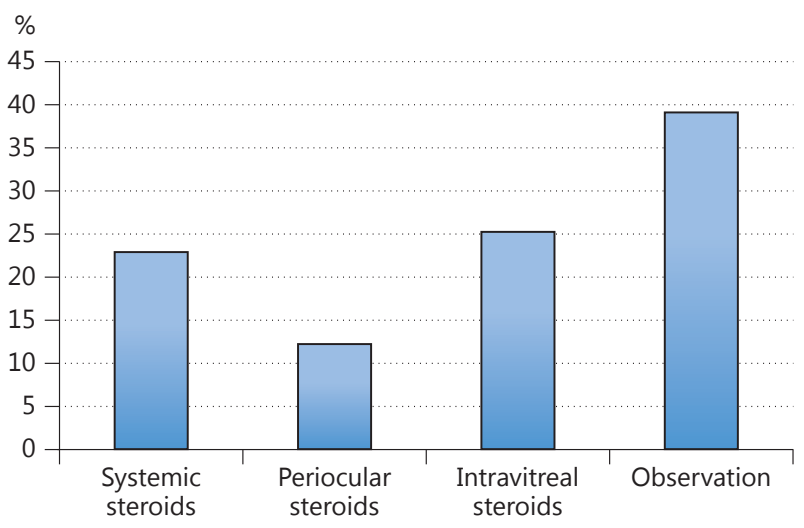

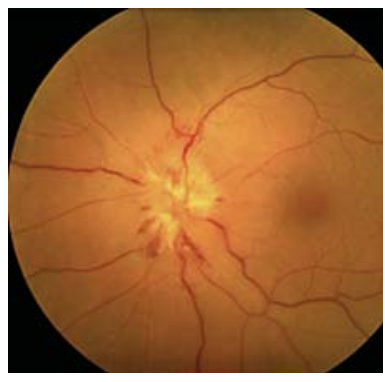

Fig. 21. Treatment of acute radiation optic neuropathy. Reproduced with permission from: Taban M, Taban M, Bolling J, Singh AD: Ocular complications of radiotherapy; in Singh AD, Damato BE, Pe'er J, Murphree AL, Perry JD (eds): Clinical Ophthalmic Oncology. Philadelphia, Saunders-Elsevier, 2007, pp 45-49.

ation optic neuropathy would be observed by $39 \%$ of the respondents and treated with steroids by others (fig. 21). Laser photocoagulation was most frequently (64\%) recommended for a small retinal capillary hemangioma (von Hippel-Lindau disease) (fig. 22), whereas cryotherapy was the preferred method for a retinal vasoproliferative tumor (fig. 23). The preferred treatment of circumscribed choroidal hemangioma (symptomatic) was photodynamic therapy (74\%) and radiation therapy for diffuse choroidal hemangioma (75\%) (fig. 24). Progressive leakage in a case of retinal astrocytoma would be treated by photodynamic therapy (43\%) or laser photocoagulation (27\%) (fig. 25).

\section{Conjunctival Tumors}

For diagnosis of conjunctival squamous cell carcinoma, a biopsy in all nonsurgical cases or in atypical cases was favored by the majority (94\%). Diagnostic exfoliative cytology was recommended by only $6 \%$ of the respondents (fig. 26). For management of a localized tumor, combined surgical excision and cryotherapy were most frequently advised (77\%) (fig. 27). Exploration of the role of topical chemotherapy for conjunctival squamous cell carcinoma revealed that the majority prescribed it as adjuvant therapy (49\%), whereas it was also used 
Singh et al.: A Small Step towards Big Data: Trends and Preference Patterns in

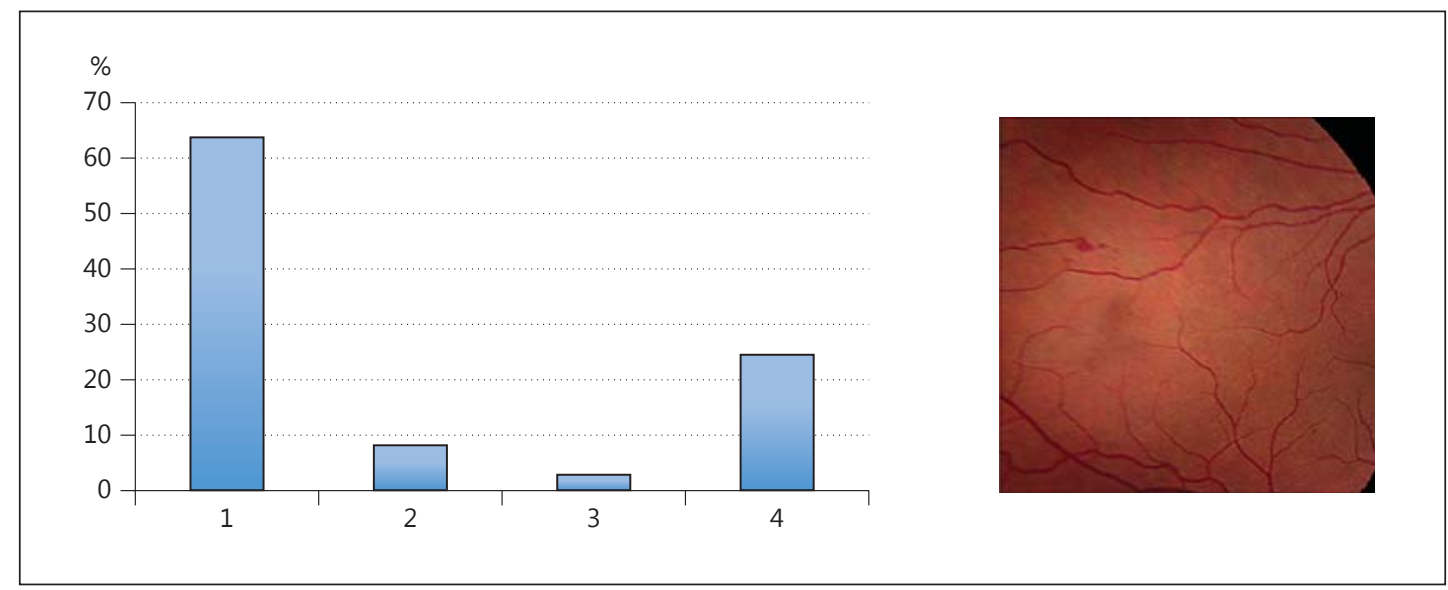

Fig. 22. Treatment of a small retinal capillary hemangioma (von Hippel-Lindau disease). (1) Laser photocoagulation. (2) Photodynamic therapy. (3) Anti-VEGF therapy. (4) Observation. Reproduced with permission from: Singh AD: Ocular phototherapy. Eye (Lond) 2013;27:190-198.
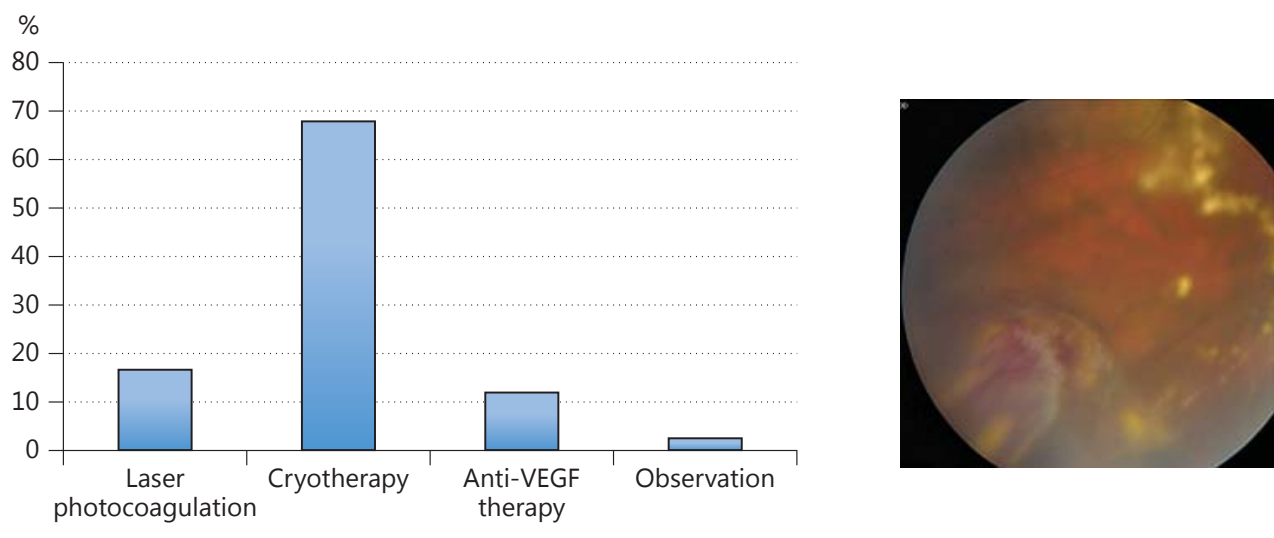

Fig. 23. Treatment of a retinal vasoproliferative tumor.

Fig. 24. Treatment of circumscribed choroidal hemangioma (symptomatic) and diffuse choroidal hemangioma. (1) Observation. (2) TTT. (3) Photodynamic therapy. (4) Radiation therapy.

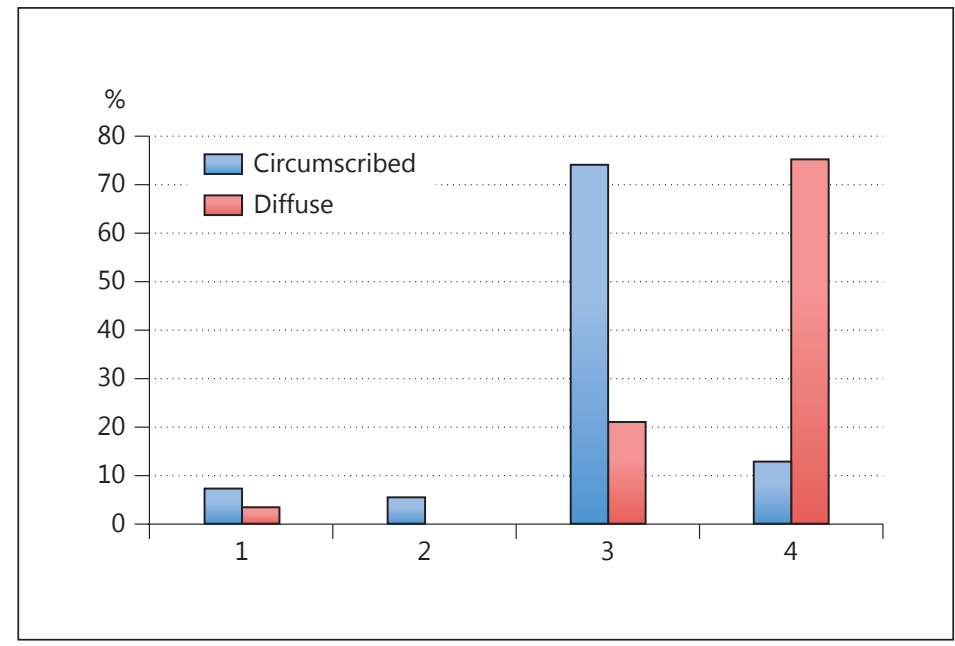


Singh et al.: A Small Step towards Big Data: Trends and Preference Patterns in

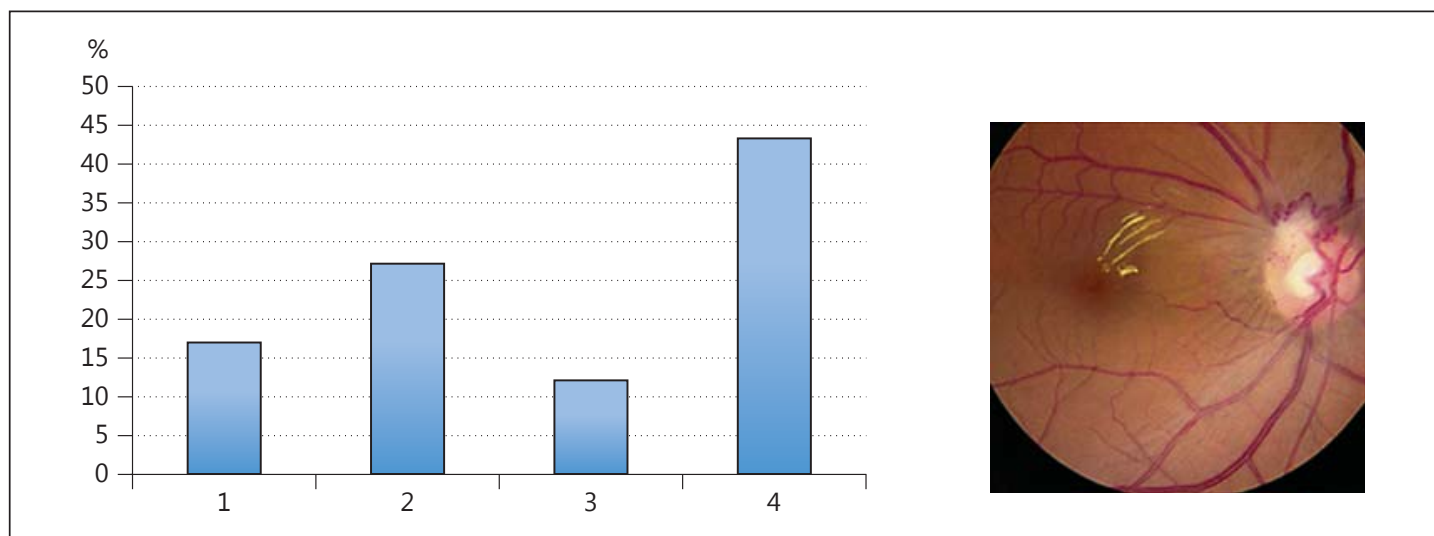

Fig. 25. Treatment of retinal astrocytoma associated with progressive leakage. (1) Observation. (2) Laser photocoagulation. (3) Photodynamic therapy. (4) TTT. Reproduced with permission from: Singh AD: Neoplastic diseases of the retina; in Agarwal A (ed): Gass' Atlas of Macular Diseases, ed 5. Philadelphia, ElsevierSaunders, 2012.

Fig. 26. Role of diagnostic biopsy in conjunctival squamous cell carcinoma. (1) Diagnostic biopsy for all nonsurgical cases. (2) Diagnostic biopsy only in atypical cases. (3) Diagnostic exfoliative cytology.

Fig. 27. Management of a localized conjunctival squamous cell carcinoma. (1) Surgical excision only. (2) Cryotherapy only. (3) Combined surgical excision and cryotherapy. (4) Topical chemotherapy only.
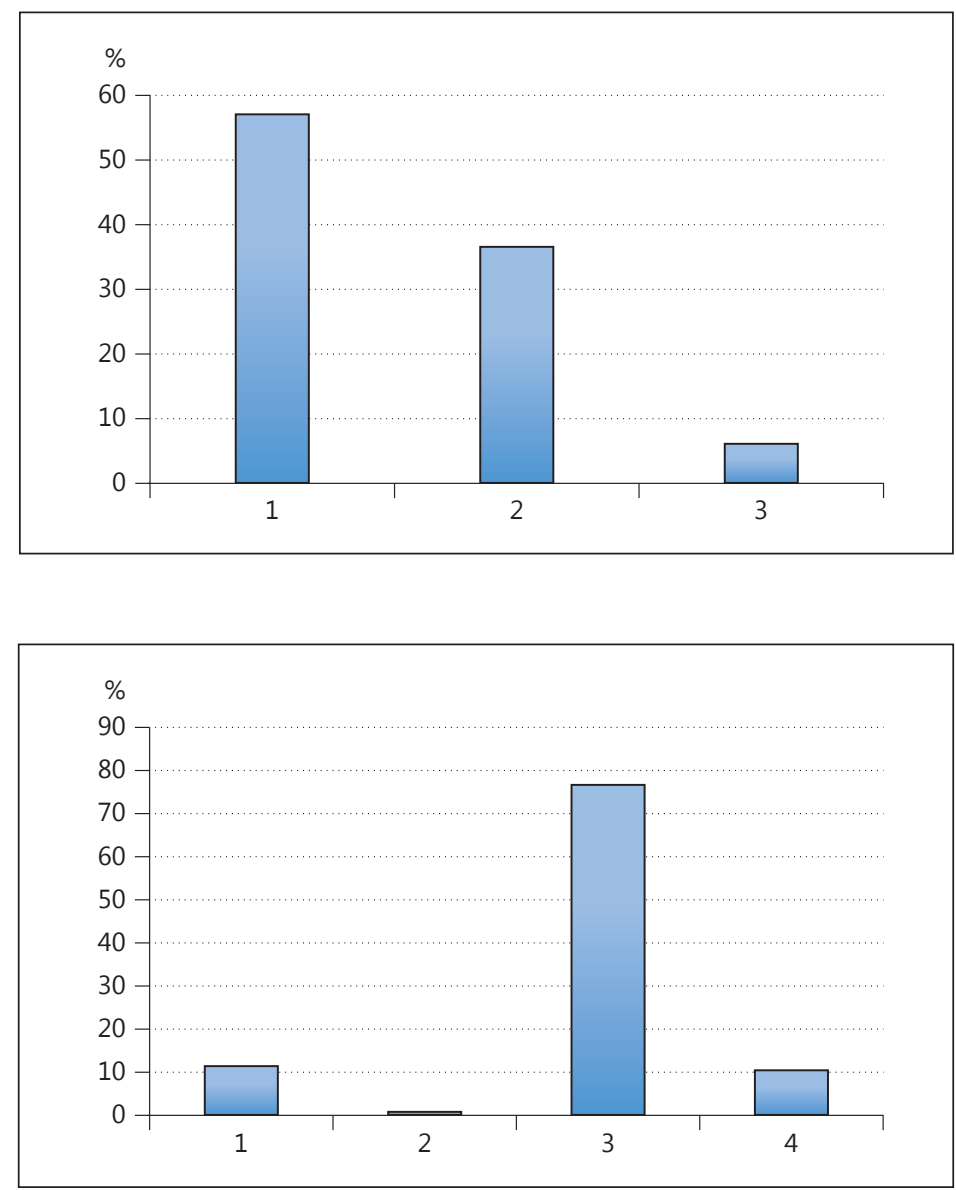

in other settings (43\%) (fig. 28). In case of a small suspected conjunctival primary acquired melanosis, the majority would either observe (53\%) or excise the lesion (42\%) (fig. 29). For a bulky conjunctival melanoma, only about one third (37\%) would advise sentinel lymph node biopsy (fig. 30). 
Ocular Oncology

and Pathology

Fig. 28. Role of topical chemotherapy in the management of conjunctival squamous cell carcinoma.

\begin{tabular}{l|l}
\hline Ocul Oncol Pathol 2015;1:39-53 \\
\hline DOI: 10.1159/000366561 & $\begin{array}{l}\text { @ 2014 S. Karger AG, Basel } \\
\text { www.karger.com/oop }\end{array}$ \\
\hline
\end{tabular}

Singh et al.: A Small Step towards Big Data: Trends and Preference Patterns in Ophthalmic Oncology

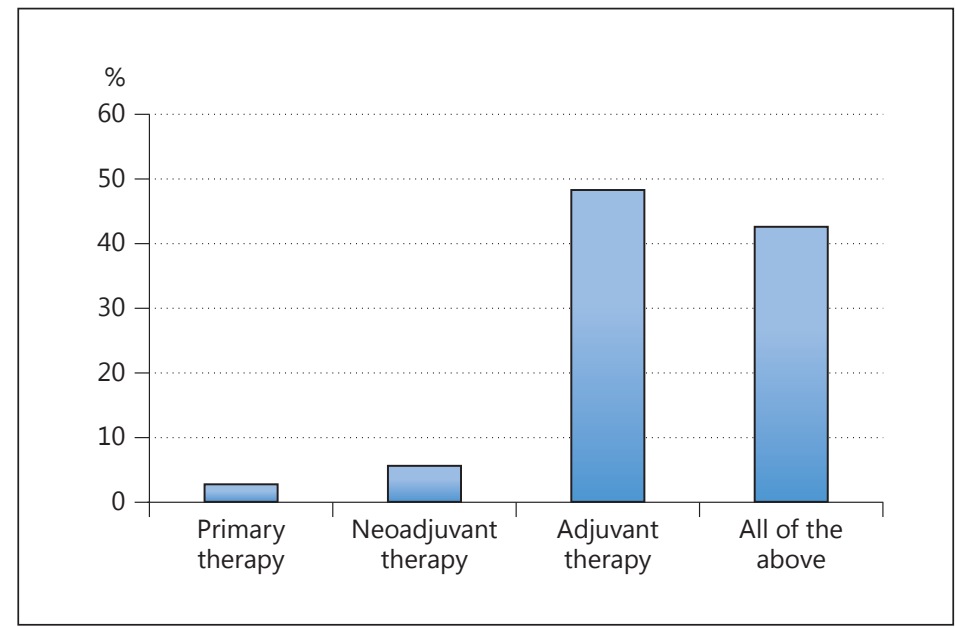

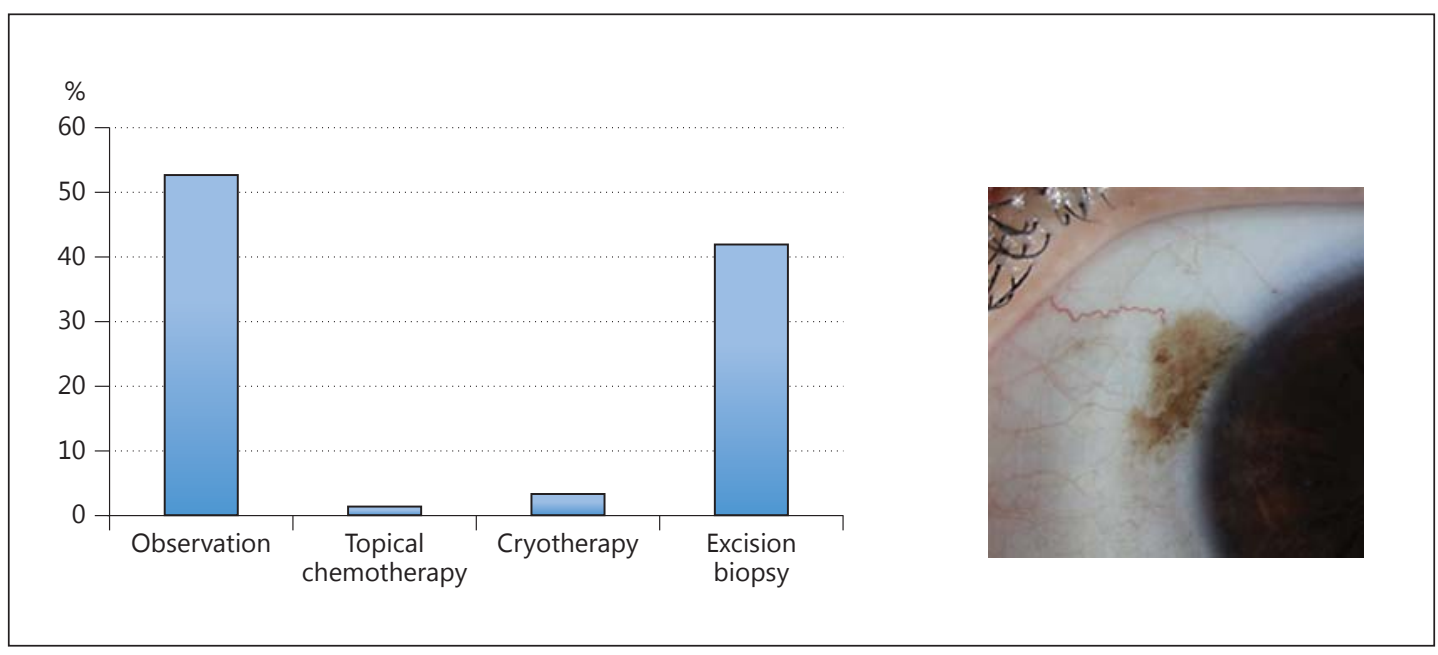

Fig. 29. Treatment of a small area of conjunctival primary acquired melanosis.

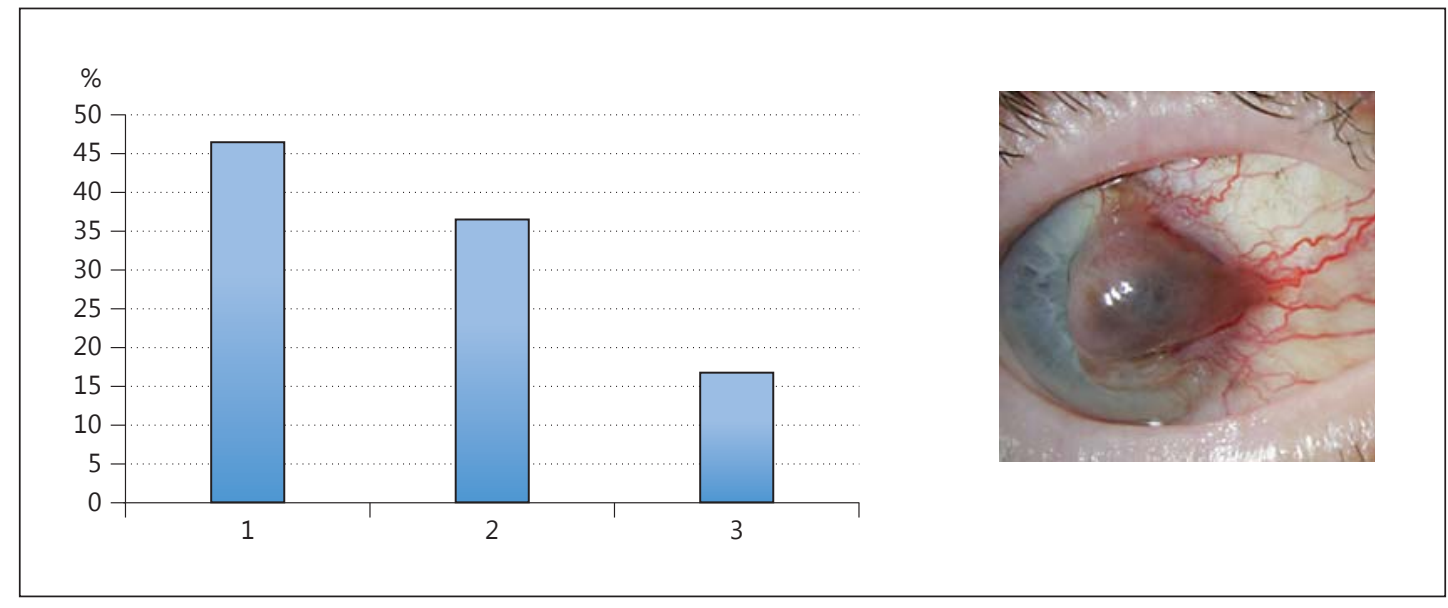

Fig. 30. Role of sentinel lymph node biopsy in conjunctival melanoma. (1) I do not advise sentinel lymph node biopsy. (2) I advise it only for selected cases. (3) I advise it for all cases. 
Ocular Oncology

and Pathology

Fig. 31. Use of orbital implant following enucleation. (1) No implant. (2) Silastic ball implant. (3) Polyethylene implant. (4) Hydroxyapatite implant. (5) Other type of implant.

Fig. 32. Wrapping material for orbital implant. Implant wrap for primary enucleation. (1) No wrapping. (2) Sclera. (3) Pericardium. (4) Fascia lata. (5) Other type of material.

\begin{tabular}{l|l}
\hline Ocul Oncol Pathol 2015;1:39-53 \\
\hline DOI: 10.1159/000366561 & $\begin{array}{l}\text { @ 2014 S. Karger AG, Basel } \\
\text { www.karger.com/oop }\end{array}$ \\
\hline
\end{tabular}

Singh et al.: A Small Step towards Big Data: Trends and Preference Patterns in Ophthalmic Oncology
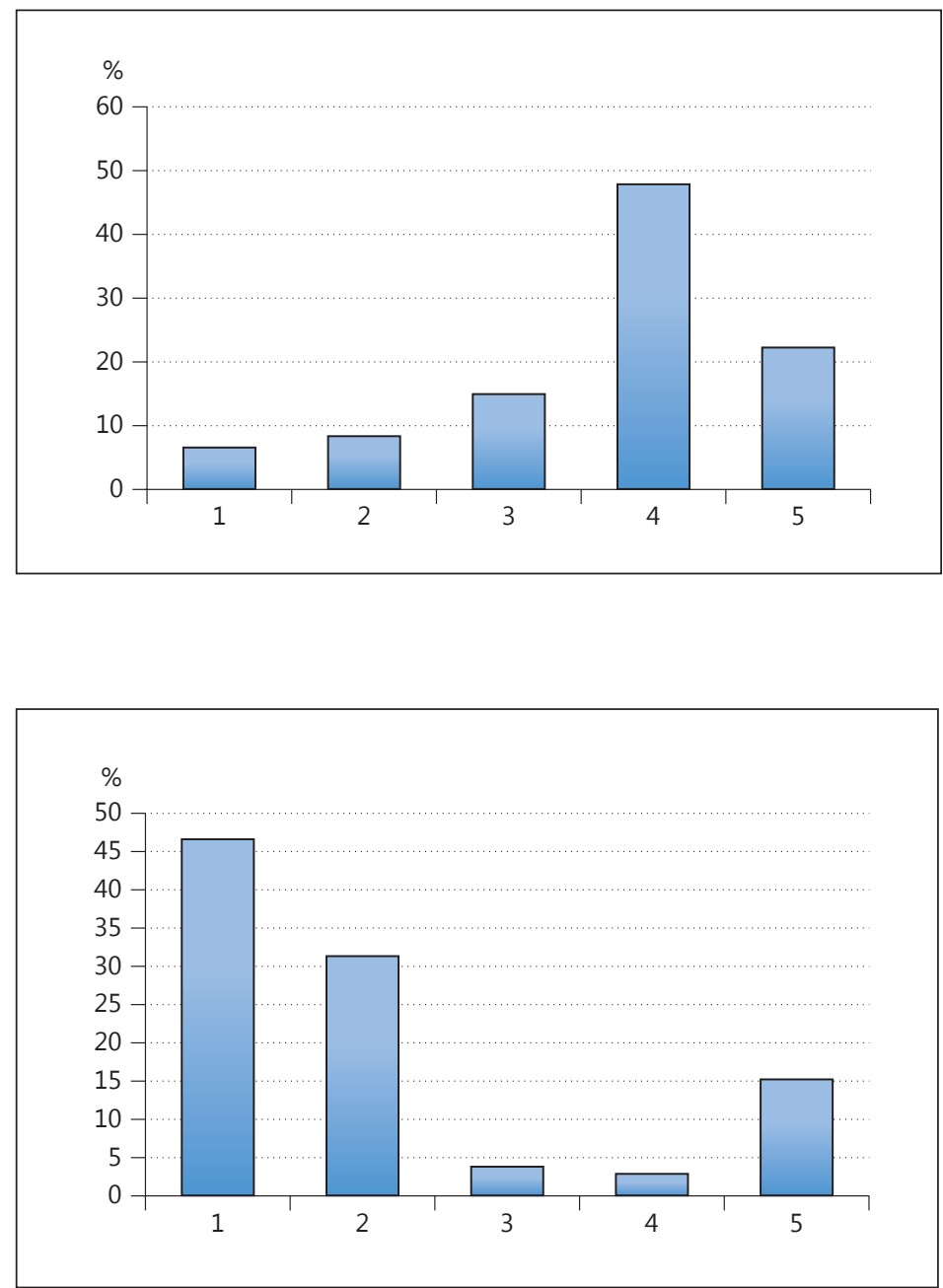

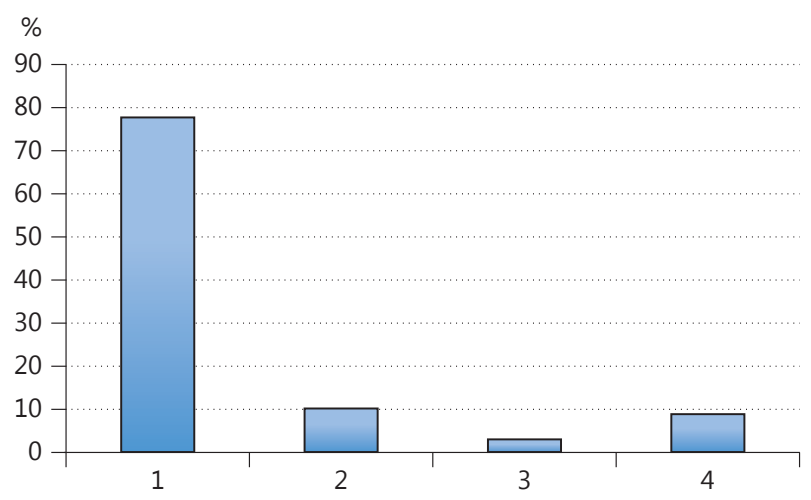

Fig. 33. Treatment options for unilateral orbital adnexal lymphoma (marginal zone type). (1) Radiation therapy. (2) Intravenous rituximab. (3) Combination. (4) Chemotherapy. 
Fig. 34. Type of biopsy for a lacrimal gland tumor suspected to be metastases. (1) No biopsy. (2) Diagnostic fine needle aspiration biopsy. (3) Incisional biopsy. (4) Excisional biopsy.

Singh et al.: A Small Step towards Big Data: Trends and Preference Patterns in Ophthalmic Oncology

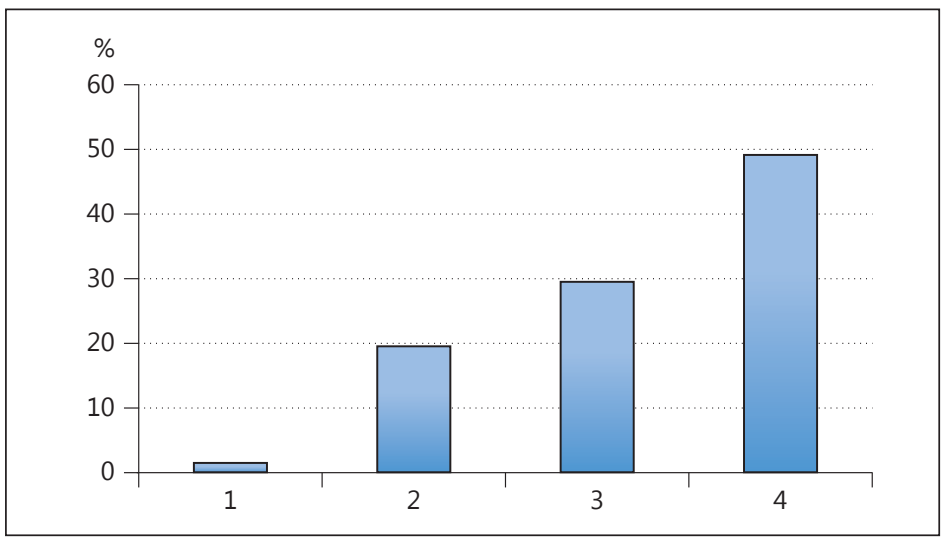

\section{Orbital Tumors}

For primary enucleation, the vast majority (63\%) used a porous implant (hydroxyapatite or polyethylene). Only a minority (7\%) did not use any kind of implant (fig. 31) or pericardium or fascia lata as the wrapping material (fig. 32). For unilateral adnexal lymphoma (marginal-zone type), the preferred method of treatment was radiation (78\%) (fig. 33). For a lacrimal gland tumor, suspected to be metastases, almost all (99\%) would prefer some form of confirmatory biopsy (fig. 34).

\section{Discussion}

To our knowledge, this paper records the first attempt at generating preference patterns among ocular oncologists for commonly encountered clinical diagnoses or scenarios. The data presented herein is not derived from studies or interventions performed on a large number of patients; therefore, it does not indicate correctness of the preferences. Rather, this paper is a compilation of preferences expressed in response to a given clinical scenario by a group of nonrandomly selected ocular oncologists derived from diverse practice environments. Nevertheless, such data collection efforts should be ongoing and comprehensive in order to collect information on trends, practice preferences, and guidelines in absence of hard evidence. 